\title{
On critical thinking and content knowledge: a critique of the assumptions of cognitive load theory
}

\author{
Dr Peter Ellerton \\ The University of Queensland Critical Thinking Project \\ Australia
}

"Thinking is the method of intelligent learning"

John Dewey

\begin{abstract}
How critical thinking is understood has a logical impact on pedagogy and curriculum design in a critical thinking education. If critical thinking is seen as a complex mix of knowledge, skills and dispositions that can be articulated and made an object of study in themselves, then there is scope for intentional and explicit targeting of such things. If, however, critical thinking is seen as a general skill more or less impermeable to pedagogical influence and best realised through the development of content knowledge, then an explicit focus on developing thinking skills is misplaced and potentially distracting. The latter view is that of cognitive load theory (CLT), a theoretical framing of thinking and learning that has gained traction in education including with practitioners. This paper will explore some of the assumptions of CLT and show that they are either (1) in error, (2) vaguely or confusingly expressed and/or (3) the conclusions drawn within the theory are often errors of inference. Moreover, I point out that important educational research that weakens the claims of CLT is often not engaged with or addressed.
\end{abstract}

Keywords: critical thinking, cognitive load theory, inquiry, pedagogy, dispositions 


\section{Introduction}

There are conflicting views about what critical thinking is. Some see it as a mix of skills and dispositions that can be developed in a variety of contexts (Siegel, Kuhn, Bayer, Lipman). Others see it as a general (innate) skill relatively immune to pedagogical influence (Sweller, Willingham). Each of these views contains assumptions that generate a variety of pedagogical approaches. Despite this incoherence, the importance of critical thinking to innovation, employability, participatory democracy and countering widespread misinformation is widely accepted, and so the means in which it is developed and the educational environments that are constructed to do this are a cause of immediate and significant concern.

Perhaps the most significant schism that exists between these views concerns the relationship of critical thinking to content knowledge. Two broad approaches are discernible. One offers that critical thinking can be developed independently or perhaps alongside of content knowledge, suggesting that there is a range of thinking skills that are themselves proper objects of study and can be meaningfully targeted for development in the classroom. Another offers that critical thinking is only meaningful in discipline area contexts, and that deep content knowledge is prerequisite to activating students' critical thinking capabilities. An example of the former is the teaching of philosophy to (mostly) primary school students through a variety of 'Philosophy for/with Children' (PC) programs that are well developed worldwide, including a substantial and historic movement in Australia (Burgh and Thornton, 2016). Based on the work of Matthew Lipman and Anne Sharp and rooted in the pragmatic philosophy of John Dewey, this movement focuses on the development of thinking skills, including those of argument analysis, construction and evaluation in the contexts of collaborative philosophical inquiry. An example of the latter are programs based on Cognitive Load Theory (CLT), developed by the educational psychologist John Sweller and echoed in educational contexts by theorisers and researchers such as Daniel Willingham. CLT sees thinking skills as an emergent property of content knowledge development and an explicit focus on teaching them as misguided and indeed unhelpful since it distracts students from the key business of content knowledge acquisition. PC programs have a strong research base indicating their effectiveness in a range of outcomes in terms of student cognitive gains. CLT theorists point to experimental evidence against the effectiveness of explicit teaching for thinking and propose arguments as to why it is pedagogically unsound. These two examples far from exhaust critical thinking approaches, but they serve as a useful contrast.

The purpose of this paper is to critically analyse claims that critical thinking cannot be explicitly taught, including claims from CLT. This analysis will concern both the understanding of critical thinking and the teaching of it.

One of the core claims of CLT is that our working memory-memory available for the shortterm storage and manipulation of information not yet committed to long term memory-is very limited and should be carefully marshalled for use in learning. Overloading students' working memory by using poorly designed instructional techniques unnecessarily complicates learning and makes it less effective. While it is understood that there is an inevitable cognitive load intrinsic to learning a task (the so-called germane load when it includes the development of understanding apart from simple recall), any additional load imposed by means of instruction (the extrinsic load) should be minimised. ${ }^{1}$ For example, it is claimed that providing worked examples minimises the extrinsic cognitive load on students

\footnotetext{
${ }^{1}$ For a fuller account of the categories of cognitive load CLT suggests see de Jong (2010).
} 
and allows them to better engage with the problem and its content, proving to be more effective in terms of learning outcomes than students developing these approaches themselves through an inquiry process (Schwonke et al., 2009).

In addition to minimising extrinsic cognitive load, it is essential, according to CLT theorists, that students can integrate their knowledge into a functional understanding of the conceptual underpinnings of their subject areas. Rather than simply memorising facts or copying procedures, students should develop a schematic representation of their subject areas that can be called upon to solve more complex problems. Knowledge which is highly and effectively integrated - schematic knowledge - is definitional of expertise across many domains; it is what allows experts to operate so quickly and accurately, partly because knowledge that is schematically organised places a much smaller demand on working memory than unintegrated knowledge allowing for more effective problem-solving. Worked examples that can minimise cognitive load seem more effective at developing schematic understanding in students, particularly in the early stages of concept development, and are hence a desirable means of optimising student learning.

Consequent to this, at the core of CLT are some key propositions:

P1: Working memory should be optimised during learning (minimised extrinsic load)

P2: "Explicit guidance and feedback from teachers is more effective in teaching students new content and skills ${ }^{2}$ than letting them discover these for themselves" (due to, among other things, the reduction in extrinsic memory requirements) (Sweller, 2019)

P3: Inquiry "should only be used when we cannot obtain needed information from others" (following on from P1 and P2) (ibid)

P4: “...to think deeply, we need lots of knowledge stored [schematically] in long-term memory" (ibid)

These propositions might seem, prima facie, sensible to some, but more on this later. Consider now another proposition that Sweller claims is intrinsic to CLT:

P5: There are two types of knowledge, "biologically primary knowledge", or knowledge we can acquire automatically (such as speaking a language) and "biologically secondary knowledge" which we must explicitly teach (most things we are taught at school), "...critical thinking is biologically primary and so unteachable." (ibid)

Leaving aside how realistic the distinction between biologically primary and secondary knowledge might be for the moment, it remains unclear why critical thinking is placed in the primary category. It seems a significant point to omit, for there seems nothing in $\mathrm{P} 1-4$ to rule out critical thinking being teachable.

Before I address this and other problems, it is worth considering a view within cognitive psychology that resonates with CLT, though this resonance is by no means a universal

\footnotetext{
2 Presumably, these skills cannot be thinking skills as CLT states that they cannot be explicitly taught.
} 
phenomenon in psychology. ${ }^{3}$ One prominent and influential voice is that of psychologist Daniel Willingham, who claims that critical thinking is both only achievable through deep discipline knowledge and non-transferable (Willingham, 2020). Willingham and cognitive load theorists seem to agree that critical thinking is an emergent property actualised by problem solving within a discipline context using schematically organised deep discipline knowledge. In this view, since critical thinking is so intimately associated with context, and hence so reliant on deep knowledge of that context, it is difficult to conceptualise it as a transferable skill. In support of this statement, Willingham notes several experimental cases in which students have been taught a variety of skills ranging from chess to computer coding that do not seem to have produced any benefits in other areas.

From this we have two final propositions to add to the list above, completing, for the purposes of this paper at least, a summary of key ideas that have significant current educational traction, including in the Australian context. ${ }^{4}$

P6: Critical thinking can only be actualised through deep content knowledge

P7: Critical thinking is not a transferable skill.

\section{What Cognitive Load Theory gets wrong}

There are at least four significant problems with the proposition set above. I will address these as follows.

\section{The definitional problem}

Before pronouncing on the teachability of critical thinking, it is necessary to understand what it is. The onus for definitional clarity is owned by both sides of the argument but let us look for the moment at the CLT view. It is unclear how critical thinking is defined in the CLT literature. Willingham (2008) calls it a "type" of thinking but does not explain how it differs from other types of thinking (or what they may be) or what the necessary conditions are for thinking to be called critical (p. 22). He also suggests that it is a type of thinking that "...even 3-year-olds can engage in - and even trained scientists can fail in" (ibid). Without recourse to more detail, these could presumably represent what is innate in critical thinking (i.e. biologically primary) in the case of the former and that we are fallible with regard to critical thinking despite being trained in discipline knowledge in the case of the latter. It is difficult, however, to reconcile claims that critical thinking requires deep discipline knowledge (P6) with the success of a three-year-old. It is also unclear how a trained scientist, presumably steeped in discipline knowledge, can get it so wrong. Presumably, the solution to the problem of the failing scientist is simply more knowledge. Or is it unavoidable because the scientist simply has a smaller allocation of biologically primary critical thinking skill than other scientists?

In helping to position this "type" of thinking, Willingham suggests activities that involve critical thinking include "playing chess, designing a product, or planning strategy for a field

\footnotetext{
${ }^{3}$ See Moreno and Moreno, 2010 for a critique of CLT as unscientific

${ }^{4}$ See the then Chief Scientist of Australia Alan Finkel's speech Master the foundations, and rule a universe (2018)
} 
hockey match" (Willingham, 2020, p. 9). It is difficult to know what to make of these suggestions. Computers can play chess, but we would not credit them with critical thinking skills, so critical thinking can't be a necessary condition for chess playing. Perhaps the intention is to say that the ability to play chess presents some elements of a broader definition of critical thinking. Or perhaps not, it is hard to tell. Plotting chess moves (by humans if not computers) of course requires conditional (if-then) thinking and some pattern recognition and response but it is a tough call to say that critical thinking is exhausted by chains of deductive inferences and analysis and evaluation of patterns - particularly given that the latter, as argued below, seems more indicative of deep domain knowledge.

Perhaps in implicit acknowledgment of their dearth of definitional clarity, cognitive load theorists propose an equivalence between critical thinking and expertise. The expert can solve problems within their domain that the rest of us cannot; and they can do so quickly and effectively. The claim seems to be that since thinking critically means thinking effectively, experts, being effective thinkers, must be thinking critically. This is in harmony with P4 (to think deeply, we need lots of knowledge stored [schematically] in long-term memory) since, as mentioned above, expert knowledge is schematically organised. These expert schemata contain knowledge of the kinds of problems domain workers face and the best ways of solving them (Glasser, 1985; Ericsson and Charness, 1994). But there are some problems with this assumption of the equivalence between critical thinking and expertise. One problem is that not all expertise seems to involve the same levels of critical thinking. Horvath and Bott (2020), for example, claim that expertise is not transferable (more on this claim later) using the example that the golfer Tiger Woods cannot transfer his skill level to, say, baseball. Doubtless learning to play golf well is, in part, a cognitive activity, but it is unclear on CLT terms how it sits aside expertise in more cognitively complex areas such as rocket science or brain surgery in terms of critical thinking requirements. Willingham often resorts to the chess expert as a paradigmatic example, but the same might be asked of that expert as of the golfer-what, exactly, is the cognitive nature of your domain and how does it relate to critical thinking? We can escape this problem on the assumption that some areas of expertise require more critical thinking than others (or at least a broader range of skills), but then using examples drawn from these more restrictive cognitive domains would have minimal force, yet this seems to be exactly where the body of experimental evidence for CLT claims is most dense (see for example Tamizi and Sweller, 1988). ${ }^{5}$

Another problem in equating expertise and critical thinking is that calls to increase critical thinking in the general population are unanswerable unless we all become experts in something. This might not be as extreme as it sounds if the call is really to simply become more informed about issues, on the assumption that we are at least moving towards expertise in an area just by learning more about it. Against this claim, however, there is much research showing that simply being exposed to more information about an issue does not improve the quality of thinking about it and that there is more to the arena of public reasoning than the amount and quality of information available (Tversky and Kahneman, 1981; Stanovich and West, 2000). Similarly, effective thinking cannot be limited to deep domain knowledge, or else we are reduced to the proposition that anyone without deep domain knowledge is incapable of effective thinking at all. Whence, then, comes Willingham's three-year-old? My own son, around the age of 6, once

\footnotetext{
${ }^{5}$ Many of the examples Sweller offers come from mathematics, particularly geometry. There is no doubt that mathematics is a cognitively demanding and complex discipline, however the kinds of thinking most students engage in during mathematics classes is overwhelmingly deductive thinking, typified by well-structured problems and single answers. Generalising learning principles from this to include, say, historical or philosophical inquiry is not well justified.
} 
asked why the moon seems to follow us in the car. After pointing out to him that the closer things are, the quicker they seem to move past us, he opined that the distance we have to move to say we went 'past' something is roughly equivalent to the distance it is from us. This kind of insight, revelatory to me despite my qualifications in physics, was critically derived, evaluated and justified using examples. Any parent can recognise moments like this as examples of children thinking well during the course of their inquiry without deep domain knowledge.

This appeal to expertise as definitional of critical thinking results in a number of "gotcha" moments that represent supposed refutations that critical thinking can be anything but content based. In a recent webinar, Horvath and Bott (2021) presented the audience with a complex physics problem and invited them to suggest what critical thinking skills they would use to solve it. Clearly this problem is unsolvable without relevant physics knowledge and thus supposedly elevates the truism that 'if you are thinking critically, then you must be thinking about something' into a knock down argument against any context-neutral conception of critical thinking. But this represents a flawed inference. Just because physics knowledge is a necessary condition to solve that problem, it does not mean that (1) the problem requires much in the way of critical thinking and (2) even if it did, that physics knowledge is sufficient to think effectively about the problem. This also extends to any claims of schematic knowledge in that it may be necessary to thinking effectively (in some cases and for some problems) but it does not mean that it is sufficient to do so. This confusion between necessary and sufficient conditions is emblematic of many such arguments from CLT regarding critical thinking.

Cognitive load theorists may try to get around this problem by claiming that domain knowledge may not be sufficient in itself, but that the critical thinking skills needed to also solve the problem can only be activated through the use of domain knowledge and that these skills are biologically primary anyway. Basically, the more domain knowledge (and only more domain knowledge), the more critical thinking that can occur. The way to falsify this claim would be to seek evidence that (1) critical thinking skills can be explicitly identified and taught and that (2) this teaching makes a difference to student performance. This leads us to a second problem with CLT.

\section{The experimental problem}

Let all the experimental results finding that worked examples and other well-directed teacher strategies lower extrinsic cognitive load and improve schematic understanding remain unchallenged. Let us also accept that well organised schemata are at the heart of expert performance. None of this leads to the conclusion that critical thinking is biologically primary, that it reduces to expertise or that it cannot or should not be explicitly taught. The only possible evidence that it cannot be taught is that, if the cognitive load theorists are to be believed, attempts to teach it in the past have failed. In any attempt at teaching critical thinking, the null hypothesis is that the intervention will have no discernible effect on student performance, but this requires some specificity of conditions. First, that the skills attempting to be taught are both well identified and clearly constitutive of critical thinking; second, that the teaching of them is done well; third, that doing so makes a difference in student performance in assessment tasks; and fourth, that the assessment tasks require critical thinking to succeed. Much of what is offered by CLT in support of the null hypothesis does not meet these conditions or cannot be shown to meet them. 
Willingham proffers that attempts to teach computational thinking, learning to play a musical instrument or learning chess have not succeeded as "all-purpose enhancers of intelligence" (Willingham, 2020, p.6). He then goes on to say that "it is no surprise then that programs in school meant to teach general critical thinking skills have had limited success" (ibid) without defining what these programs are (they are not all about chess or music) or what success means. Of the many problems with this assertion, one is that none of these examples meet the conditions outlined above. Another is that the distinction between intelligence and critical thinking is not explained. Indeed, they seem to be treated by Willingham as synonymous. Perhaps this is an echo of the assumption of CLT that critical thinking is biologically primary, something often attributed to intelligence (Garlick, 2002). If Willingham means improving intelligence when he speaks about teaching critical thinking, then that is a very different proposition from what is normally implied in educational contexts. This assumption would explain, however, the belief that the only way to improve the effectiveness of critical thinking is to improve schematic understanding since intelligence is a better (though still arguable) candidate for something 'biologically primary'.

In addressing the issue of the nature of success, Willingham laments that in programs in which logical and spatial puzzles are taught, the assessment tends to also be logical and spatial. The same is true for teaching argumentation, in which the assessment is to evaluate arguments (Willingham, 2020, P.6). Why this is problematic is not clear, since these things can be thought of as elements of critical thinking. If the goal is to teach such things, testing them would seem salient. But, of course, these skills are especially meaningful if they can be transferred across a variety of domain contexts, something Willingham says is only minimally evident if at all. As evidence, he cites Ritchart \& Perkins'(2005) thoughtful analysis of teaching for thinking programs, which found variable evidence for the success of teaching for thinking. But while the evidence was indeed variable across programs, some, including Philosophy for Children, showed significant success according to a series of criteria including transferability of thinking skills (ibid, p. 779). This work is highlighted by Topping and Trickey (2007), whose seminal paper noted significant and sustained gains in students' cognitive ability following training in collaborative philosophical inquiry with an explicit focus on thinking skills, including those measured by transferable effects, that lasted years after the intervention. ${ }^{6}$ Van Gelder, Bisset and Cumming (2004) have also noted an improvement of up to 0.8 SD in the critical thinking abilities of students who have constructed and evaluated arguments via argument mapping as measured by independent testing (p.147). This is as much of a gain after one semester as you typically find after a 4-year degree (ibid, p.148). Further work also shows the value of a guided, metacognitive approach to thinking focusing on the intentional, self-directed deployment of cognitive assets, the lack of which is a significant factor in explaining limited success in transferability in some programs (Kuhn, 1999; 2000). The absolute claim of CLT that "critical thinking is unteachable" is clearly refuted by these studies. As is the claim that it is not transferable. The softer claim that it is best done through a context of engagement with deep content knowledge is also challenged by these findings. Claiming critical thinking is not directly susceptible to pedagogical influence beyond content development stands in contrast to a significant body of research and pedagogical practice that does not seem to be engaged with or addressed by CLT.

A further experimental problem for CLT concerns the nature of scientific investigation, a core function of which is to propose and attempt to falsify hypotheses via the hypothetico-deductive

\footnotetext{
${ }^{6}$ Willingham address another study of Topping and Trickey (Willingham, 2008, p.28), giving a critique of its methodology but not refuting its findings.
} 
method. A proposed hypothesis must make testable (in principle) predictions allowing the possibility of falsification. CLT conceptions of cognitive load types, however, are not well supported by evidence (de Jong, 2009). Thus, hypothesis formation and predicting from them is problematic. Consequently, "cognitive load theory is constructed in such a way that it is hard or even impossible to falsify...[and]...every outcome fits within the theory post-hoc" (ibid, p. 125). This "post-hoc" adaptation of data typically characterises investigations as unscientific. Moreover, compelling scientific evidence that the two types of learning identified withing CLT (primary and secondary) is lacking, and certainly the claim that populating these categories can be done with precision and accuracy remains unjustified. ${ }^{7}$

\section{The inquiry problem}

Propositions 1-3 can be taken as a group, since there seems to be some inferential connection between them. It is because extraneous cognitive load is minimised through worked examples that "explicit guidance and feedback from teachers is more effective in teaching students new content" and this supposedly justifies why inquiry-students discovering for themselves how to solve a problem - is a last resort.

Unsurprisingly, the examples offered as evidence for these propositions all involve problems for which optimal pathways to solutions already exist and are well-established. Many are based in mathematics as noted earlier, with geometry problems famously foregrounded. To be charitable, there seems nothing wrong about the claim that this clutch of propositions can deliver basic proficiency in a range of cases, including those usually presented in the literature. Much could be meaningfully adapted along these lines. But to infer from this that these propositions encompass all optimal learning experiences is to commit a non-sequitur. Even granting cases of well-defined processes existing in other subject areas, there are many instances of student learning that are not so structured, or even that might eschew that structure for other gains.

Take the case of Year 10 students determining the factors that affect the period of a pendulum. It does not seem pedagogically misguided for a teacher to discuss with the group what these factors could potentially be, to ask them how they might be measured and controlled for, and to request that they draw up a list of materials and procedures they could use to capture data. Students could then suggest ways to present and analyse the data and attempt to falsify or confirm any hypotheses they may have developed. During this time, students will generate ideas and hypotheses, explain and justify their thinking to the group, evaluate potential courses of action, and develop collaborative skills to produce a final product. This entire process need not involve any worked examples. Granted that it would be more efficient in terms of knowledge transmission to simply tell students the answer in accordance with P3, but that would diminish the skills development just outlined. What's more, the gains in student engagement through a dialogic and collaborative approach would be lost (Gillies, 2020; Kuhn, 2015), as would the realistic experience of what doing science collaboratively is like. None of this worthwhile activity seems to permeate or even be accounted for in a CLT approach.

CLT suggests that schematic understanding of a domain is a precursor to thinking well within it and that this understanding is sufficient to activate innate critical thinking skills. A deep

\footnotetext{
${ }^{7}$ Chomsky's Universal Grammar would seem to be a more sophisticated example of something "biologically primary", though even this is disputed.
} 
assumption of CLT, therefore, is that there is no schematic structure of inquiry that can add to this domain knowledge. But there are such structures, and they are well understood. For example, Walton et al. (2008) have outlined a wide range of argument schemata that generate critical inquiry questions to be used precisely in the absence of sufficient data. Van Gelder et al.'s (2004) paper "Cultivating Expertise in Informal Reasoning” demonstrates how expertise in informal reasoning can be explicitly developed through argument mapping. Cook et al. (2018) have identified a schematic process to debunk claims that mainstream climate science can be refuted, relying on argument analysis and inferential integrity rather than deep content knowledge. Going more deeply into the nature of reasoning itself, Mercier and Sperber (2011) offer evidence that the evolutionary function of reason is the prosecution and evaluation of arguments rather than truth-seeking, positioning it as a means of improving communication and hence understood better as a social competence than an individual faculty. Dismissing inquiry as unnecessary or unhelpful is therefore both hasty and slothful.

Perhaps most critically since inquiry is the means of production of knowledge, a wilful disregard for inquiry and a focus only on knowledge transmission does not bode well for the creation of knowledge-makers. What this implies for a knowledge economy definitionally geared to the production of new knowledge is potentially fraught. As for designing a product, Willingham's earlier example of a critical thinking activity, it is interesting to consider what parts of the process require critical thinking. An elucidating example is found in entrepreneurial education, a fundamental focus of developing a knowledge economy. One of the defining characteristics of entrepreneurial endeavours is that no clear answer or solution is available prior to beginning the process. Indeed, even the nature of the problem may not be clearly understood. In phases of exploration and consolidation, entrepreneurs engage in creative and critical thinking but do not necessarily have an in-depth knowledge of the domain in which they are operating. They are, rather, defined by their tolerance of ambiguity and willingness to test assumptions and hypotheses before committing to courses of action as opposed to being passive recipients of knowledge (Higgins and Elliott, 2011). How this is subject to a 'worked example' model is difficult to apprehend; indeed, the methodologies of CLT seem antagonistic to entrepreneurial education, or at least seem to offer little towards it, reflecting an indifference to the character of the learner. This indifference indicates a further problem.

\section{The agential problem}

One contention is that good critical thinkers make their thinking itself an object of study (Ellerton, 2020). In particular, they identify and analyse their assumptions with intentionality and care, they check the quality of the inferences they make, they seek others to test their thinking, and they analyse, construct and evaluate arguments with as much care for inferential integrity as they have for the specifics of their content area. Good critical thinkers are also concerned with issues of character, working with an appreciation of intellectual integrity, openmindedness and a tolerance for diverging perspectives. Some of the most well-cited definitions of critical thinking refer to character, including Siegel's notion of good thinkers as being "appropriately moved by reasons" (1998, p.23).As Bailin and Battersby (2016) note, this appreciation of character traits is characteristic of virtue, and these aspects of character which are geared towards effective inquiry are understood as intellectual virtues (see, for example, Elder and Paul, 1988). 
A virtue is not just a tendency to behave in a certain way but a tendency to do so based on an appreciation or valuing of the enterprise (Bailin and Battersby, 2016, p. 368)

Annas (1995) also supports this concept of appreciation, recognising that virtue contains "some kind of intellectual structure, accessible to the reflective agent" (p.233).

What we might call the virtuous inquirer, therefore, is someone who cares for the quality of their thinking and actively nurtures characteristics that they wish to develop for their own inquiry ends. It follows that the virtuous inquirer is, to a significant degree, self-directed, autonomous and reflective with an ability and willingness to act on the outcomes of their reflections.

CLT offers no recognition of the learner as an autonomous agent, focusing on a passive account of learning that is more a function of the instruction environment than the individual learner. It is not only silent with regard to inquiry virtues, but also at odds with a great deal of educational research and practice that can be included under the banner of Self-Regulated Learning (SRL) (see Panadero, 2017 for a review).

The idea of inquiry virtues aligns with what we know of expertise. If, as CLT seems to suggest, expertise is synonymous with, or at least necessary for, critical thinking, and critical thinking is biologically primary, we might expect that the difference in expertise between individuals similarly trained would be a function of their innate or primary capabilities. Ericsson et al. (1993) have shown, however, that intelligence and expertise are unrelated. Indeed, the factor that seems to promote expertise is reflection upon the relationship between action and thinking in the domain of expertise. This "deliberate practice" (ibid) is a metacognitive, intentional focus on knowledge creation, modification and application that goes beyond a passive transmission of knowledge or acquiescence to a given methodology and speaks to self-directed and deliberative learning in context. As an old adage goes, you can't make someone an expert - they need, ultimately, to do it for themselves.

\section{Conclusion}

An argument that the effectiveness of thinking can be improved by content knowledge is no argument that critical thinking cannot be taught. And it is certainly no argument that critical thinking is best promoted by a sole focus on developing content knowledge with no attention given to quality of reasoning. The vagueness within CLT of what critical thinking is, along with a misunderstanding of the distinction between necessary and sufficient conditions, the conflation of terms such as critical thinking, expertise and intelligence, and the unfounded assertions of critical thinking as biologically primary results in a plethora of poor-quality inferences from experimental data that impact negatively on the imperative to develop the critical thinking abilities of students.

Considering the success of programs that have been shown to develop the quality of student thinking by explicitly focusing on reasoning skills, there seems room for optimism that welldesigned pedagogical and curriculum approaches can continue to be developed and implemented given a more precise and purposeful understanding of critical thinking. There also seems no need to promote a false dichotomy between teaching for thinking and content 
development in terms of pedagogical focus. As they are co-targets in the noun sense, so both can be targeted in the verb sense. As Ritchart \& Perkins note:

The idea that deep and lasting learning is a product of thinking provides a powerful case for the teaching of thinking. Indeed, we venture that the true promise of the teaching of thinking will not be realized until learning to think and thinking to learn merge seamlessly (2005, p.795).

But let me give the last words to Dewey, who so often in the space of education has had the first:

Thinking is the method of intelligent learning (1966, p.152)

This article has benefited from collaborative discussions with Professor Deborah Brown, University of Queensland, Professor Calvin Normore, University of California, Los Angeles and Dr Claudio Mazzola, University of Queensland. 


\section{References}

Annas, J. (1995). Virtue as a skill. International Journal of Philosophical Studies, 3(2), 227243. https://doi.org/10.1080/09672559508570812

Atkinson RK, Derry SJ, Renkl A, Wortham D. Learning from Examples: Instructional Principles from the Worked Examples Research. Review of Educational Research. 2000;70(2):181-214. doi:10.3102/00346543070002181

Bailin, S., \& Battersby, M. (2016). Fostering the Virtues of Inquiry. An International Review of Philosophy, 35(2), 367-374. https://doi.org/10.1007/s11245-015-9307-6

Burgh, G., \& Thornton, S. (2016). Philosophy goes to school in Australia: A history 19822016. Journal of Philosophy in Schools, 3(1), 59-83.

Cook, J., Ellerton, P., \& Kinkead, D. (2018). Deconstructing climate misinformation to identify reasoning errors. Environmental Research Letters, 13(2), 024018.

de Jong, T. (2010). Cognitive load theory, educational research, and instructional design: Some food for thought. Instructional Science, 38(2), 105-134.

https://doi.org/10.1007/s11251-009-9110-0

Dewey, J. (1966), Democracy and Education, New York: Free Press

Elder, L., \& Paul, R. (1998). Critical Thinking: Developing Intellectual Traits. Journal of Developmental Education, 21(3), 34. Periodicals Archive Online.

Ellerton, P. (2020, September 10). On critical thinking and collaborative inquiry. NSW Department of Education. https://education.nsw.gov.au/teaching-and-learning/education-fora-changing-world/resource-library/on-critical-thinking-and-collaborative-inquiry.html

Ericsson, K. A., \& Charness, N. (1994). Expert Performance. American Psychologist, 49(8), 725-747. doi:10.1037/0003-066X.49.8.725

Ericsson, K. A., Krampe, Ralf Th, \& Tesch-Romer, Clemens. (1993). The Role of Deliberate Practice in the Acquisition of Expert Performance. Psychological Review, 100(3), 363-406.

Garlick, D. (2002). Understanding the nature of the general factor of intelligence: The role of individual differences in neural plasticity as an explanatory mechanism. Psychological Review, 109(1), 116-136. https://psycnet.apa.org/doi/10.1037/0033-295X.109.1.116

Gillies, R., Dialogic Teaching during Cooperative Inquiry-Based Science: A Case Study of a Year 6 Classroom. (2020). Education Sciences, 10(11), 328.

https://doi.org/10.3390/educsci10110328

Glaser, R., Chi, M. T. H., \& Farr, M. J. (1988). The nature of expertise / [edited by] Michelene T.H. Chi, Robert Glaser, M.J. Farr. Hillsdale, N.J. : L. Erlbaum Associates. 
Higgins, D., \& Elliott, C. (2011). Learning to make sense: What works in entrepreneurial education? Journal of European Industrial Training, 35(4), 345-367.

https://doi.org/10.1108/03090591111128324

Kuhn, D. (1999). A Developmental Model of Critical Thinking. Educational Researcher, 28(2), 16-46. https://doi.org/10.2307/1177186

Kuhn, D. (2000). Metacognitive Development. Current Directions in Psychological Science, 9(5), 178-181. https://doi.org/10.1111/1467-8721.00088

Jared Cooney Horvath. (2021, April 14). The Problem With Teaching 21st Century Skills (10 Things Schools Get Wrong: Book Launch Webinar \#2). https://www.youtube.com/watch?v=vcZXbOUwVEM

Kuhn, D. (2015). Thinking Together and Alone. Educational Researcher, 44(1), 46-53. https://doi.org/10.3102/0013189×15569530

Horvath, J., \& Bott, David. (2020). 10 Things Schools Get Wrong (And How We Can Get Them Right). John Catt Educational.

Lipman, M. (1976). Philosophy for children. Metaphilosophy, 7(1), 17-39. Retrieved May 13, 2021, from http://www.jstor.org/stable/24435193

Master the foundations, and rule a universe | Chief Scientist. (2018). Retrieved June 17, 2021, from https://www.chiefscientist.gov.au/2018/07/opinion-master-the-foundations-andrule-a-universe

Moreno, R., \& Moreno, R. (2010). Cognitive load theory: More food for thought. Instructional Science, 38(2), 135-141. https://doi.org/10.1007/s11251-009-9122-9

Panadero, E. (2017). A Review of Self-regulated Learning: Six Models and Four Directions for Research. Frontiers in Psychology, 8, 422. https://doi.org/10.3389/fpsyg.2017.00422

Ritchhart, R., \& Perkins, D. N. (2005). Learning to think: The challenges of teaching thinking. The Cambridge Handbook of Thinking and Reasoning, 775-802.

Schwonke, R., Renkl, A., Krieg, C., Wittwer, J., Aleven, V., \& Salden, R. (2009). The worked-example effect: Not an artefact of lousy control conditions. Computers in Human Behavior, $S$

Siegel, H. (1989). Epistemology, critical thinking, and critical thinking pedagogy. Argumentation, 3(2), 127-140. https://doi.org/10.1007/bf00128144

Siegel, H. (2017). Education's epistemology: Rationality, diversity, and critical thinking. Oxford University Press. https://doi.org/10.1093/oso/9780190682675.001.0001

Stanovich, K. E., \& West, R. F. (2000). Individual Differences in Reasoning: Implications for the Rationality Debate? Behavioral and Brain Sciences, 23(05), 645-665. 
Sweller, J. (2021, April 21). Five questions to ask if you think teaching problem-solving works. EduResearch Matters. https://www.aare.edu.au/blog/?p=9210

Sweller, J. (2019). I had an idea in the 1980s and to my surprise, it changed education around the world. The Conversation https://theconversation.com/i-had-an-idea-in-the-1980s-and-tomy-surprise-it-changed-education-around-the-world-126519

Tarmizi, R. A., \& Sweller, J. (1988). Guidance during mathematical problem solving. Journal of Educational Psychology, 80, 424-436.

Topping, K. J., \& Trickey, S. (2007). Collaborative Philosophical Enquiry for School Children: Cognitive Effects at 10-12 Years. British Journal of Educational Psychology, 77(2), 271-288. https://doi.org/10.1348/000709906X105328

Tversky, A., \& Kahneman, D. (1981). The framing of decisions and the psychology of choice. Science, 211(4481), 453-458. https://doi.org/10.1126/science.7455683

Van Gelder, T., Bissett, M., \& Cumming, G. (2004). Cultivating Expertise in Informal Reasoning. Canadian Journal of Experimental Psychology/Revue Canadienne de Psychologie Expérimentale, 58(2), 142-152. https://doi.org/10.1037/h0085794

Van Gelder, T. (2005). Teaching critical thinking: Some lessons from cognitive science. College Teaching, 53(1), 41-46.

Walton, D., Reed, C., \& Macagno, F. (2008). Argumentation Schemes. Cambridge: Cambridge University Press. https://doi.org/10.1017/CBO9780511802034

Willingham, D. T. (2008). Critical Thinking: Why Is It So Hard to Teach? Arts Education Policy Review, 109, 21-32. https://doi.org/10.3200/AEPR.109.4.21-32

Willingham, D. (2020, September 10). How to teach critical thinking. NSW Department of Education. https://education.nsw.gov.au/teaching-and-learning/education-for-a-changingworld/resource-library/how-to-teach-critical-thinking.html 